University of Wollongong

Research Online

Faculty of Business - Papers (Archive)

Faculty of Business and Law

January 2017

On the carrying capacity and the optimal number of visitors in tourism destinations

Simone Marsiglio

University of Wollongong, simonem@uow.edu.au

Follow this and additional works at: https://ro.uow.edu.au/buspapers

Research Online is the open access institutional repository for the University of Wollongong. For further information contact the UOW Library: research-pubs@uow.edu.au 


\title{
On the carrying capacity and the optimal number of visitors in tourism destinations
}

\author{
Abstract \\ Tourism specialization on the one hand may be a successful tool to achieve fast economic growth, and, \\ on the other hand, may be detrimental for natural resources. Finding the right balance between economic \\ benefits and environmental costs is essential to reach sustainable development, ensuring that tourist \\ numbers do not exceed the carrying capacity of the tourism destination. In this context, the author \\ analyses the determination of the optimal number of visitors in a tourism-based economy, and shows that \\ if the tourist number is optimally determined long-run sustainable growth will be possible. He also shows \\ that the optimal number of tourists is strictly smaller than the carrying capacity of the tourism \\ destination, and that such a condition is vital to achieve long-run growth.

\section{Publication Details} \\ Marsiglio, S. (2017). On the carrying capacity and the optimal number of visitors in tourism destinations. \\ Tourism Economics: the business and finance of tourism and recreation, 23 (3), 632-646.
}




\title{
On the carrying capacity and the optimal number of visitors in tourism destinations
}

Tourism Economics

2017, Vol. 23(3) 632-646

(C) The Author(s) 2016

Reprints and permission: sagepub.co.uk/journalsPermissions.nav DOI: 10.5367/te.2015.0535 journals.sagepub.com/home/teu

@SAGE

\author{
Simone Marsiglio \\ University of Wollongong, Australia
}

\begin{abstract}
Tourism specialization on the one hand may be a successful tool to achieve fast economic growth, and, on the other hand, may be detrimental for natural resources. Finding the right balance between economic benefits and environmental costs is essential to reach sustainable development, ensuring that tourist numbers do not exceed the carrying capacity of the tourism destination. In this context, the author analyses the determination of the optimal number of visitors in a tourism-based economy and shows that if the tourist number is optimally determined long-run sustainable growth will be possible. He also shows that the optimal number of tourists is strictly smaller than the carrying capacity of the tourism destination, and that such a condition is vital to achieve long-run growth.
\end{abstract}

\section{Keywords}

carrying capacity, economic growth, natural resources, optimal tourist numbers

\section{Introduction}

Tourism is often viewed as a powerful engine of growth and development for several developing economies (especially, small island countries); however, the number of tourists a destination receives dramatically impacts on the environmental, social, and cultural resources of the region. In particular, tourism is based on a deep and complex relationship with the surrounding environment, which affects and is affected by tourists' inflows (Budowski, 1976). Thus, managing tourist numbers to achieve a balance between development and the environment is crucial if the tourist region is to be economically viable in the long run (Mohan et al., 2007). Because of this delicate problem, in literature much emphasis is placed on the need to identify the carrying capacity of a tourist destination, that is, the maximum number of tourists a destination can accommodate.

\section{Corresponding author:}

Simone Marsiglio, School of Accounting, Economics and Finance, University of Wollongong, Northfields Avenue, Wollongong 2522 NSW, Australia.

Email: simonem@uow.edu.au. 
The notion of carrying capacity can be considered from a wide range of different perspectives and thus does not have one clear definition. The term carrying capacity is generally interpreted as the largest number of tourists an economy can fit based on maximum use of the land and space available. However such a "physical" constraint is unlikely to be reached as other factors are likely to limit the number of tourists to a lower level (Rey-Maquieira et al., 2004). Indeed, the concept of carrying capacity needs to be extended to encompass environmental aspects, ${ }^{1}$ in order to determine a threshold beyond which the damage to the natural ecosystem becomes irreversible (Briguglio, 2008), or to consider the amount of tourism that can be accommodated with minimal damage to the environment (Wilkinson, 1989). In fact, economic considerations only have a tendency to cause tourist destinations to overshoot that level of carrying capacity set by ecological requirements (De Albuquerque and McElroy, 1992) and thus it is important to incorporate also environmental carrying capacity measures into development plans. The concept of carrying capacity of tourist destinations is mainly discussed in relation to the quality of the tourist experience, such that carrying capacity represents the maximum number of visitors that a destination can fit without the quality of the tourist experience deteriorating (Canestrelli and Costa, 1991; Hovinen, 2002); alternatively it is described as the limit of the "... resources (human and physical) to absorb the effects of tourism so that tourism and other activities and attributes would be able to be maintained over the long term" (Butler, 1999). Once the maximum tourist number is exceeded, negative outcomes result at human and environmental levels, such as in resident's attitudes to tourism; consequently the nature of the destination may change, becoming less attractive to tourists, and tourism may decline ${ }^{2}$ (Butler, 1999; Giannoni and Maupertuis, 2007). However, whatever is the adopted definition of carrying capacity, there is likely to be a level whereby "... crowding and environmental deterioration is such that the tourist experience in an area is no longer worthwhile ... [and this level] ... is already beyond the socially optimal tourist load" (Tisdell, 1987).

Thus, determining what is the carrying capacity of tourism destinations may be essential to reach long run sustainable development. However, while carrying capacity sets a maximum number of tourists for a sustainable tourism activity, this number may not be the optimal level as visitors bring costs as well as benefits; the optimal level of visitors should be related to securing optimal environmental, social and economic gains for the location being visited (Bramwell, 1997). Different locations incur differing costs and benefits; hence, the optimal scale of tourism, including tourist numbers and the level of investment in natural, physical, and social capital to support the tourism industry, will also differ across locations (Candela and Cellini, 2006). This eventual difference between carrying capacity and optimal tourist number requires some further investigation on what are the determinants of the optimal size of tourism activities. However, only few studies try to identify what is the optimal number of tourists in specific destinations given the need of preserving the cultural or natural environment of the hosting region. ${ }^{3}$ Most of these works do not adopt an economic but an operational research approach, by relying on linear programming methodologies, which even if allowing to exactly quantify this number for specific destinations cannot be used to derive policy recommendations. Specifically, Canestrelli and Costa (1991) using fuzzy programming techniques show that Venice could bear about 25,000 visitors a day; or similarly, Feliziani and Miarelli (2012) estimate that the optimal number of tourists in Rome is around 300,000 per day. To the best of our knowledge, only Cerina (2007) tries to analyze the issue from an economic point of view. ${ }^{4}$ In particular, he develops a simple growth model driven by natural resources able to balance the economic benefits and environmental costs associated with tourism development. However, since the economic constraint he considers is static, the model abstracts from capital accumulation and economic growth turns out to be exogenous. In this article, 
we borrow Cerina's (2007) approach and extend his model along the lines of Marsiglio (2015) in order to enrich the economic dynamics, by allowing for endogenous (tourism) capital accumulation and a deeper economic-environmental interaction.

The article proceeds as follows. The section "The model" develops our dynamic general equilibrium model focusing on tourism-based economies, where crowding averse tourists are attracted by the stock of natural amenities and the stock of tourism facilities available in the economy. The social planner needs to manage the trade-off between developing tourism facilities and preserving natural resources, by deciding how many tourists to allow in the domestic economy. Indeed, a larger number of tourists will lead on the one hand to larger income and on the other hand to stronger pressure on the natural ecosystem, which may result in less tourists in the future. In section "BGP equilibrium and transitional dynamics," we analyze the steady-state outcome, and we show that the economy converges in the long run to its sustainable balanced growth path (BGP) equilibrium, along which the number of tourists is constant while consumption, income, tourism, and natural capital grow at constant rates. The section "The effects of environmental shocks" presents the possible effects of exogenous shocks not only along the BGP but also along the transition toward the BGP, showing that (environment-driven) tourism destinations may be very strongly affected by environmental and climatic shocks, thus policy makers need to play a very important role in limiting the depletion of natural resources. The section "Discussion" briefly discusses and interprets our results highlighting possible policy implications. In section "Conclusion," as usual we present some concluding remarks and propose directions for future research. Online Appendix contains additional details about the planner's optimization problem and the role of the transversality conditions and the boundedness of the objective function in imposing certain parameter restrictions.

\section{The model}

The model is a Ramsey-type (1928) model of optimal growth where the social planner seeks to maximize the welfare of the society (i.e. the residents) subject to the economic and environmental dynamic constraints. We adopt the framework developed in Cerina (2007), and later adopted by Lozano et al. (2008) and Marsiglio $(2015,2016)$, to describe the international tourism market and tourist preferences. ${ }^{5}$ Specifically, we consider a small economy producing only tourism services (accommodation, restaurants, leisure facilities, etc.), supplied in an international tourism market populated by a large number of tourism economies (tourists' flow comes from the international market and there is no distinction between resident and nonresident tourists). The notion of tourism services we adopt in this article should be interpreted as a bundle of goods and services able to satisfy a wide range of tourism consumers (Candela and Figini, 2010). The international demand for tourism is infinite at the price level corresponding to tourists' willingness to pay and nil for any other price level. Thus, the equilibrium quantity of tourism is totally determined by the supply side. $^{6}$

The welfare is the infinite discounted sum ( $\rho$ is the pure rate of time preference) of instantaneous utilities; the utility function is assumed to be iso-elastic in its unique argument, consumption, $c_{t}: u\left(c_{t}\right)=\frac{c_{t}^{1-\sigma}-1}{1-\sigma}$, where $\sigma>0$ is the inverse of the intertemporal elasticity of substitution. Residential population is assumed to be constant, and its level is normalized to 1 for the sake of simplicity. The economic constraint is given by the law of motion of tourism capital, which is given by the difference between residents' income and consumption: $\dot{k}_{t}=y_{t}-c_{t}$. Income totally depends upon tourism revenues, which are given by the product between tourists' willingness to 
pay for and the quantity of tourism service exchanged on the market. The willingness to pay depends on the stock of tourism services, $k_{t}$, the stock of natural resources, $e_{t}$, and the number of tourists in the tourism destination, $z_{t}$, and it is assumed to take a Cobb-Douglas form, $p_{t}=A k_{t}^{\alpha} e_{t}^{\phi} z_{t}^{-\mu}$, where $A$ is a scale parameter while $\alpha, \phi \in(0,1)$ and $\mu \in(-1,1)$ measure tourists' sympathy toward tourism facilities, natural amenities, and presence of other visitors in the tourism destination, respectively. In particular, if $\mu>0$ tourists are crowding averse, if $\mu=0$ crowding indifferent while if $\mu<0$ crowding lover. Since $\phi$ and $\alpha$ represent tourists' preference toward natural amenities and human-built facilities, we refer to them as the green preference and grey preference parameters (Marsiglio, 2015). For the sake of simplicity, it is assumed that each tourist buys one unit of tourism services, such that $y_{t}=A k_{t}^{\alpha} e_{t}^{\phi} z_{t}^{1-\mu}$. The environmental constraint is represented by the law of motion of natural resources, which are assumed to be a stock variable (Marsiglio, 2011). Natural capital ${ }^{7}$ grows over time according to the difference between the natural rate of environmental regeneration, $r$, and the pressure generated by tourism activities, $\eta z_{t}$, where $\eta$ measures the intensity of tourism exploitation of natural resources: $\dot{e}_{t}=\left(r-\eta z_{t}\right) e_{t}$. Since the stock of natural resources depletes because of tourism activities, we are representing Budowsky's (1976) conflict scenario ${ }^{8}$ between tourism and environment. Thus, the planner by determining the number of tourists to allow in the local economy trades off the economic benefits of tourism and the associated environmental costs.

The planner optimization problem consists of choosing the level of consumption and the number of tourists to allow in the tourism destination, taking into account the dynamic evolution of tourism capital, natural resources, and their given initial conditions, $k_{0}$ and $e_{0}$ :

$$
\begin{aligned}
\max _{c_{t}, z_{t}} W & =\int_{0}^{\infty} \frac{c_{t}^{1-\sigma}-1}{1-\sigma} e^{-\rho t} \mathrm{~d} t \\
\text { s.t. } \quad \dot{k}_{t} & =A k_{t}^{\alpha} e_{t}^{\phi} z_{t}^{1-\mu}-c_{t} \\
\dot{e}_{t} & =\left(r-\eta z_{t}\right) e_{t} .
\end{aligned}
$$

Note that if international tourism demand continues to increase over time (as recent worldwide trends and forecasts show; WTTC, 2013), allowing tourist numbers to rise without bound will be detrimental not only for the environment but also for the economy, since tourism income will be driven to 0 (see equations (3) and (2), respectively). Thus, a careful control of tourist arrivals is actually needed in order to promote long-run economic growth. In particular, the number of tourists should not exceed the (ecological) carrying capacity, representing the maximum number of tourists which could be accommodated without leading to excessive environmental deterioration. Specifically, in our framework, the carrying capacity consists of that maximum number of tourists, $\tilde{z}_{t}$, yielding a level of deterioration equal to the regeneration capacity ${ }^{9}$ :

$$
\tilde{z}_{t}=\frac{r}{\eta} \equiv \tilde{z}
$$

Equation (4) shows that the carrying capacity is constant, thus the number of tourists which can be welcomed without excessive ecological damages is constant too. The only possibilities to observe an increase in $\tilde{z}$ are related to increases in the renewal capacity, $r$, of decreases in the tourism environmental pressure, $\eta$. While the former is to a large extent out of human control, the 
second element can be directly affected by policy makers by developing or promoting greener(ecofriendly) tourism activities.

Similarly to Marsiglio (2015), since sufficiency for the previous maximization problem requires that tourists are crowding averse, $\mu \in(0,1)$, from now onward we restrict our analysis to the situation in which $\mu>0$. Necessary and sufficient conditions yield to the following Euler equations for consumption and tourist number, respectively:

$$
\begin{gathered}
\frac{\dot{c}_{t}}{c_{t}}=\frac{1}{\sigma}\left[\alpha A k_{t}^{\alpha-1} e_{t}^{\phi} z_{t}^{1-\mu}-\rho\right] \\
\frac{\dot{z}_{t}}{z_{t}}=\frac{1}{\mu}\left[\phi r+\frac{\phi \mu}{1-\mu} \eta z_{t}-\alpha \frac{c_{t}}{k_{t}}\right] .
\end{gathered}
$$

Equation (5) is the standard Keynes-Ramsey rule for consumption and states that consumption growth increases with the income to tourism capital ratio $\left(\frac{y_{t}}{k_{t}}\right)$ and decreases with the rate of time preference. Equation (6) states that the growth rate of the number of tourists increases with the number of tourists itself and the rate of environmental regeneration, while it decreases with the consumption to tourism capital ratio $\left(\frac{c_{t}}{k_{t}}\right)$.

\section{BGP equilibrium and transitional dynamics}

We now focus on the steady-state outcome of our tourism destination, which is characterized by a BGP equilibrium, that is, a path along which all the variables grow at constant rates. At equilibrium, it is clear from equation (2) that the growth rate of tourism capital and consumption must be equal in order to have long-run growth, $\gamma \equiv \gamma_{c}=\gamma_{k}$. Moreover, from (6), the number of tourists needs to be constant, which implies that the growth rate of natural capital, $\gamma_{e}$, and that of income, $\gamma_{y}$ must be constant too. It is therefore possible to show that along the BGP, the optimal number of tourists, $\bar{z}$, the growth rate of the economy, $\gamma$, and environment, $\gamma_{e}$, are constant and strictly positive. In order to formally prove this and characterize $\gamma, \gamma_{e}$, and $\bar{z}$, we need to analyze the transitional dynamics of the tourism-based economy. Since from the previous discussion the economy shows long-run growth, the system of differential equations defined by (2), (3), (5), and (6) does not show any stationary equilibrium. Thus, in order to study the model's transitional dynamics, it may be convenient to introduce the following intensive variables, $\chi_{t}=\frac{c_{t}}{k_{t}}$ and $\varphi_{t}=k_{t}^{\alpha-1} e_{t}^{\phi} z_{t}^{1-\mu}$, which allow us to recast it in a stationary system of three differential equations:

$$
\begin{gathered}
\frac{\dot{\chi}_{t}}{\chi_{t}}=\frac{\alpha-\sigma}{\sigma} A \varphi_{t}+\chi_{t}-\frac{\rho}{\sigma} \\
\frac{\dot{\varphi}_{t}}{\varphi_{t}}=(\alpha-1) A \varphi_{t}+\frac{\mu-\alpha}{\mu} \chi_{t}+\frac{\phi r}{\mu} \\
\frac{\dot{z}_{t}}{z_{t}}=\frac{\phi r}{\mu}+\frac{\phi \eta}{1-\mu} z_{t}-\frac{\alpha}{\mu} \chi_{t} .
\end{gathered}
$$

The steady state of the system (representing the BGP equilibrium), found by setting the previous equations equal to 0 , is given by $(\bar{\chi}, \bar{\varphi}, \bar{z})$, where:

$$
\bar{\chi}=\frac{\mu(1-\alpha) \rho+(\sigma-\alpha) \phi r}{\alpha[\sigma(1-\mu)+\mu-\alpha]}
$$




$$
\begin{gathered}
\bar{\varphi}=\frac{(\mu-\alpha) \rho+\phi \sigma r}{\alpha A[\sigma(1-\mu)+\mu-\alpha]} \\
\bar{z}=\frac{(1-\mu)[(1-\alpha) \rho+(\sigma-1) \phi r]}{\phi \eta[\sigma(1-\mu)+\mu-\alpha]} .
\end{gathered}
$$

Provided that $\sigma>1$ as suggested by empirical evidence, a sufficient condition for $(\bar{\chi}, \bar{\varphi}, \bar{z})$ to be strictly positive is $\sigma \phi r>(\alpha-\mu) \rho$. By plugging equation (11) into equation (5) and plugging equation (9) into equation (3), it is immediate to obtain the economic and environmental growth rates in the tourism-based economy, given by $\gamma=\frac{\phi r-(1-\mu) \rho}{\sigma(1-\mu)+\mu-\alpha}$ and $\gamma_{e}=\frac{1-\alpha}{\phi} \gamma$, respectively. Provided that $r>\frac{1-\mu}{\phi} \rho$ both the economic and environmental growth rates are strictly positive, and whenever this latter condition is met also the condition $\sigma \phi r>(\alpha-\mu) \rho$, required for the steady state $(\bar{\chi}, \bar{\varphi}, \bar{z})$ to be well defined, is automatically satisfied.

In order to study the transitional dynamics of the system, we can proceed via linearization, obtaining the Jacobian matrix, which evaluated at steady state reads as:

$$
J(\bar{\chi}, \bar{\varphi}, \bar{z})=\left[\begin{array}{ccc}
\bar{\chi} & -\frac{\sigma-\alpha}{\sigma} A \bar{\chi} & 0 \\
\frac{\mu-\alpha}{\mu} \bar{\varphi} & -(1-\alpha) A \bar{\varphi} & 0 \\
-\frac{\alpha}{\mu} \bar{z} & 0 & \frac{\phi}{1-\mu} \eta \bar{z}
\end{array}\right] .
$$

It is straightforward to show that the associated eigenvalues are $\lambda_{1}=\frac{\phi}{1-\mu} \eta z>0$, $\lambda_{2}=\frac{1}{2}\left(\Gamma+\sqrt{\Gamma^{2}+4 \Theta}\right)>0$, and $\lambda_{3}=\frac{1}{2}\left(\Gamma-\sqrt{\Gamma^{2}+4 \Theta}\right)<0$, where $\Gamma=\frac{\alpha(1-\alpha) \rho+(\sigma-1) \phi r}{\alpha[\sigma(1-\mu)+\mu-\alpha]}>0$ and $\Theta=\frac{[(\mu-\alpha) \rho+\phi \sigma r][\mu(1-\alpha) \rho+(\sigma-\alpha) \phi r]}{\alpha \sigma \mu[\sigma(1-\mu)+\mu-\alpha]}>0$. Thus, since two eigenvalues are positive and one is negative, the steady-state $(\bar{\chi}, \bar{\varphi}, \bar{z})$, and thus our BGP equilibrium, is saddle point stable. We can summarize this discussion in the following proposition.

Proposition 1. Assume $r>\frac{1-\mu}{\phi} \rho$ and $\sigma>1$; then, the following results hold:

(i) Along the BGP, the optimal number of tourists is constant, strictly positive, and equal to:

$$
\bar{z}=\frac{(1-\mu)[(1-\alpha) \rho+(\sigma-1) \phi r]}{\phi \eta[\sigma(1-\mu)+\mu-\alpha]},
$$

while the economic and environmental growth rates are strictly positive and respectively given by:

$$
\begin{gathered}
\gamma \equiv \gamma_{c}=\gamma_{k}=\gamma_{y}=\frac{\phi r-(1-\mu) \rho}{\sigma(1-\mu)+\mu-\alpha}, \\
\gamma_{e}=\frac{1-\alpha}{\phi} \gamma .
\end{gathered}
$$


(ii) The BGP equilibrium is saddle-point stable.

The technical conditions $r>\frac{1-\mu}{\phi} \rho$ and $\sigma>1$ in proposition 1 are required in order to ensure that the growth rates and the number of tourists are strictly positive, as discussed earlier (see also the Online Appendix for some further details). While the former of these two conditions follows directly from the fact that the objective function (1) needs to be bounded, the latter is consistent with empirical evidence. Provided that these conditions are met, the tourism-based economy converges toward its BGP equilibrium along a saddle path. This means that given the initial conditions $k_{0}$ and $e_{0}$, a unique combination $\left(c_{0}, z_{0}\right)$ ensures such a converging behavior. Note that the BGP equilibrium is sustainable since it leads to constant increases in economic and environmental variables ${ }^{10}$. However, for this result to be true tourism growth, meant as increases in tourist number, cannot continue indefinitely. Indeed, in the long run, the number of arrivals has to remain constant, and this means that tourism growth will need to cease in order to ensure that natural resources are preserved, and thus they will continue to attract new tourists in the future. This result is different from what suggested by Butler (1980), since tourism-based economies do not have to end up in stagnation if natural resources are carefully managed; however, as Butler (1980) hypothesizes increases in tourist numbers cannot continue forever. The results are also different from Marsiglio's (2015), since in his model by assuming a direct relationship between tourist inflows and environmental resources, tourism growth does not have any limit, as long as some resources are devoted to clean up the environment. Note, however, that our framework is more realistic, since we do not hypothesize any one-to-one relationship between tourist inflows and natural resources.

By investigating the characteristics of the BGP equilibrium with a simple comparative statics exercise, it is possible to understand how different parameters affect the growth rates and optimal number of tourists. Similarly to what shown in Marsiglio (2015) it is clear that the economic growth rate increases with the crowding aversion, green preference, and gray preference parameters; the environmental growth rate instead increases with the green preference and crowding aversion parameters but decreases with the gray preference parameter. More interesting is understanding how the optimal tourist number is related to the model parameters, and how thus it can be affected by certain policies. ${ }^{11}$

Proposition 2. Along the BGP, the optimal tourist number is a positive function of the grey preference parameter $(\alpha)$, the inverse of the intertemporal elasticity of substitution $(\sigma)$, the rate of time preference $(\rho)$, and the natural rate of regeneration $(r)$; it is a negative function of the green preference $(\phi)$, crowding aversion $(\mu)$, and environmental pressure $(\eta)$ parameters.

Proof. The result is immediate by differentiating (13), with respect to the relevant parameter.

Proposition 2 shows that a larger degree of crowding aversion or passion toward natural amenities will reduce the optimal number of tourists to allow in the local economy, while a larger degree of passion toward tourism facilities will increase their number. The mechanism underlying this type of outcome is pretty intuitive: the number of tourists determines the deterioration of natural resources and the crowd in the tourism destination, thus when $\mu$ and $\phi$ are large, it is convenient to limit the number of arrivals in order to increase tourism revenues. Contrarily, when $\alpha$ is large tourists are not much concerned about natural amenities and prefer to rely on human-built facilities in order to satisfy their recreational needs; clearly in this case limiting the number of arrivals to reduce environmental damages (and eventual congestion effects) does not represent the 
best strategy. Very similar is the explanation of why the optimal tourist number increases with a larger rate of regeneration and decreases with a stronger environmental pressure. These two parameters rule the accumulation of natural capital, and thus the environmental growth rate: if $r$ increases or $\eta$ decreases, it is possible to accommodate a larger number of tourists maintaining the same $\gamma_{e}$ (the carrying capacity increases). The impact of $\sigma$ and $\rho$ deserves some further explanations. The rate of time preference determines the weight attached to the future, and a larger $\rho$ represents the situation in which residents care less about future events. Thus, if the rate of time preference rises, since less care is attached to future income, it becomes less stringent the need to control environmental deterioration and therefore the optimal number of tourists increases. The inverse of the intertemporal elasticity of substitution measures the elasticity of marginal utility; thus if $\sigma$ increases the consumption smoothing incentive (due to the concavity of the utility function) becomes stronger, and in a context of sustained growth, this means that future income streams need to be lowered. This is done by increasing the optimal number of tourists, which drives down the environmental growth rate and thus future income.

The main implication of proposition 2 lies in the fact that it can be directly used to determine eventual policy interventions. Indeed, our model considers maximization of welfare as the unique objective of the social planner. However, reality is generally more complex, and several goals are often simultaneously pursued. Imagine that the social planner or any other (tourism) authority wishes also to meet a certain goal in terms of visitor numbers; then proposition 2 suggests which tools allow to increase or decrease the optimal number of tourists, without implementing suboptimal policies dampening economic growth. If $\bar{z}$ needs to be increased, the goal may be achieved by implementing ad hoc policies aiming to increase the gray preference parameter, the inverse of the intertemporal elasticity of substitution, the rate of time preference, or the rate of regeneration. If it needs to be decreased, the policy has to increase the green preference, crowding aversion, and environmental pressure. Among these parameters, the simplest to affect with certain economic policies is $\eta$; indeed environmental regulation may determine which kind of tourism activities is allowed in a specific area and thus may directly determine the impact of tourism of the natural ecosystem. Moreover, by affecting $\eta$, it is possible to reach the desired goal in terms of visitor numbers without altering $\gamma$ and $\gamma_{e}$.

A further investigation of the BGP outcome allows to directly compare equations (4) and (13), in order to understand what is the relationship between the carrying capacity and the optimal number of tourists.

Proposition 3. Along the BGP, the optimal number of tourists is strictly smaller than the (ecological) carrying capacity of the tourist destination, $\bar{z}<\tilde{z}$.

Proof. The result is straightforward from the fact that along the BGP $r>\frac{1-\mu}{\phi} \rho$ holds.

Proposition 3 clearly shows that the optimal tourist number is lower than the maximum number of tourists that a tourism-based economy can accommodate. This result is intuitive. The carrying capacity is associated with a null environmental growth rate, meaning that if the tourist numbers are allowed to reach $\tilde{z}$, natural capital will remain steady at a constant level; this will directly affect tourism income and consumption, which will not be able to grow indefinitely. Therefore, from the planner's point of view, it is more convenient to exploit the power of natural capital as a potential engine of growth, reducing the number of visitors in order to ensure that the environmental growth rate is strictly positive. If the tourist number is lower than $\tilde{z}$, then income and consumption will grow indefinitely and the tourism destination will enjoy economic and environmental improvements. This simply explains why the social planner balancing the tradeoffs associated with tourism 


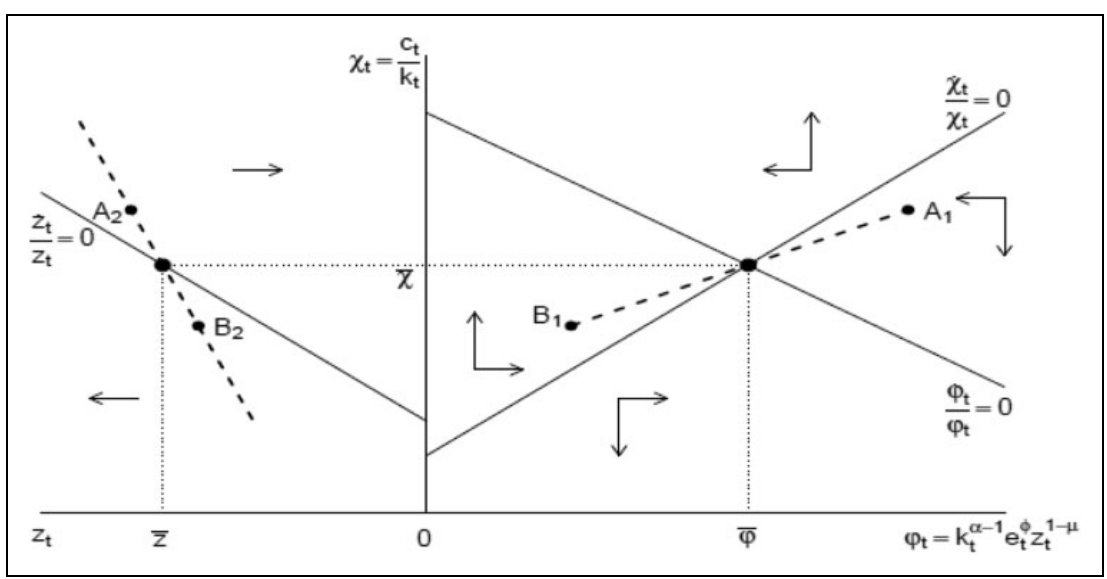

Figure I. Phase diagram of the system (7), (8), and (9). The stable arm is shown by the dashed lines.

activities cannot find it optimal to allow the tourist number to reach the maximum number that the local economy is able to accommodate. This result confirms Bramwell's (1997) intuition that optimal tourist number and carrying capacity are different concepts, and thus the planning of tourism development should be based not on the basis of the latter but the former notion.

\section{The effects of environmental shocks}

We now analyze the effects of exogenous shocks, and in particular environmental shocks, on tourism destinations by considering their impacts not only along the long-run BGP equilibrium but also along the short-run transitional dynamics. In order to discuss the impacts of such shocks in the simplest possible way, we rely upon a diagrammatic analysis based on the phase diagram associated with the system of differential equations (7), (8), and (9), as shown in Figure 1. The dashed lines represent the stable arm, that is the path taken by the (jumpable) control variables, $c_{t}$ and $z_{t}$, and the (nonjumpable) state variables, $k_{t}$ and $e_{t}$, in order to bring the system toward its steady state, and it is straightforward to not that since the equilibrium is saddle-point stable (see proposition 1) a unique converging path exists. We can also assert directly from the phase diagram how the tourism-based economy may respond to different shocks.

Consider first an environmental shock temporarily lowering the stock of natural resources, $e_{t}$ (as, e.g. a cyclone-induced sea-level rise decreasing the availability of square meters of beaches); this will clearly have some negative consequences for the economic and tourism performance of the destination, since natural resources are an important driver of tourism revenues. However, since the shock is temporary only it will not generate permanent effects, since over time as soon as the effects of the shock vanish (the sea-level returns to its preshock stage), the economy will return to its original BGP equilibrium. In order to understand how the economy may react to the shock, we need to understand what it may initially imply for the variables $\chi_{t}, \varphi_{t}$, and $z_{t}$; this is, however, not straightforward since they are all jumpable $\left(z_{t}\right.$ is a control variable, while $\chi_{t}$ and $\varphi_{t}$ are transformations of the control variables $c_{t}$ and $z_{t}$ ). Thus, they could all either increase (generating a transition from a point like $\left\{A_{1}, A_{2}\right\}$ ) or decrease (generating a transition from a point as $\left\{B_{1}, B_{2}\right\}$ ). To understand which specific path will be followed by the tourism economy we follow the 
approach in Robertson (2002), who adopts a phase diagram analysis to show the potential consequences of demographic shocks in a two-sector economic growth model. It can be convenient thus to decompose the variable $\varphi_{t}$ as the product between a purely jumpable and a purely nonjumpable variable as follows: $\varphi_{t}=\psi_{t} z_{t}^{1-\mu}$, where $\psi_{t}=k_{t}^{\alpha-1} e_{t}^{\phi}$ is a (nonjumpable) state-like variable, with dynamics given by the following expression: $\frac{\psi_{t}}{\psi_{t}}=(1-\alpha)\left(\chi_{t}-A \varphi_{t}\right)+\phi\left(r-\eta z_{t}\right)$. If the transition is from a point like $\left\{B_{1}, B_{2}\right\}$, since both $z_{t}$ and $\varphi_{t}$ will rise then also $\psi_{t}$ will need to increase, and for this to occur, the deviation in $\chi_{t}$ (from its steady-state value, $\chi_{t}-\bar{\chi}$ ) must outweigh the deviations in $\varphi_{t}$ and $z_{t}$ (from their steady-state values, $\varphi_{t}-\bar{\varphi}$ and $z_{t}-\bar{z}$, respectively); this however is not possible since the stable arm has a slope smaller than unity (due to the fact that the $\frac{\dot{\chi}_{t}}{\chi_{t}}=0$ curve has a slope lower than one too), and thus deviations in $\chi_{t}$ need to be smaller than those in $\varphi_{t}$. Also in the case in which the transition is from a point like $\left\{A_{1}, A_{2}\right\}$, since both $z_{t}$ and $\varphi_{t}$ will fall then $\psi_{t}$ will need to increase, but in this case, the deviation in $\chi_{t}$ does outweigh the deviations in $\varphi_{t}$ and $z_{t}$. Thus any type of shock will result in a transition from a point like $\left\{A_{1}, A_{2}\right\}$, and the only difference related to the kind of shock is represented by how $c_{t}$ and $z_{t}$ will initially respond to the shock in order to ensure that all the variables $\chi_{t}, \varphi_{t}$, and $z_{t}$ overshoot their steady-state value.

In the case of a temporary reduction in natural resources, initially $z_{t}$ needs to increase more than the reduction in $e_{t}$ (in order for $\varphi_{t}$ to rise) and $c_{t}$ needs to rise; however, over time consumption will increase less rapidly than tourism capital (such that $\chi_{t}$ will fall) and tourist inflows will decrease leading the economy back to its original steady-state equilibrium. As soon as the BGP equilibrium is reached, consumption and tourism capital restart growing at the same rate (such that $\chi_{t}$ remains constant) and tourism inflows do not change. The interpretation of the transitional adjustments in the tourism destination is quite intuitive: a reduction in the stock of natural resources tends to reducresidents' income; however, such an effect can be compensated by raising tourist inflows; the increased environmental pressure generated by a larger number of visitors slows down natural resources and income growth, and thus consumption growth as well; along the transition consumption grows less rapidly than tourism capital and tourist inflows are gradually reduced to restore the optimal number of visitors. If the environmental shock rather than temporarily lowering the stock of natural resources reduces tourism capital, $k_{t}$ (i.e., a cyclone destroying tourism facilities, but not affecting natural amenities), the qualitative effect will not be very different from what just discussed; indeed, the only noticeable difference is related to the immediate impact of the shock, which requires to reduce consumption more than the fall in tourism capital in order for $\chi_{t}$ to rise; however, the following evolution of consumption and tourist numbers is identical to the above.

Let us now consider some other shock affecting tourists' preferences. Consider for example a shock lowering the green preference parameter, $\phi$ (as, e.g. a climatic shock excessively rising temperature and humidity in the destination, thus reducing the enjoyability of outdoor recreation and thus of natural amenities); this will negatively affect the tourism destination not only over the short run but also over the long run. With a lower $\phi$, the $\frac{\dot{\varphi}_{t}}{\varphi_{t}}=0$ curve will shift down while the $\frac{\dot{t}_{t}}{z_{t}}=0$ curve will both shift down and flatten out, meaning that the steady-state values of $\chi_{t}, \varphi_{t}$, and $z_{t}$ will get smaller; see equations (10), (11), and (12). Since the level of $\varphi_{t}$ (corresponding to its original equilibrium value) exceeds the new long-run value, in order to address the economy along the (new) stable arm $\chi_{t}$ needs to fall, and this requires consumption to fall; over time consumption will grow less rapidly than tourism cital (such that $\chi_{t}$ will fall) and tourist inflows will decrease leading the economy to its new steady-state equilibrium. As soon as the new BGP equilibrium is reached, consumption and tourism capital restart rising at the same rate (such that $\chi_{t}$ remains constant) and tourism inflows do not change, but both the economic growth rate and tourist 
numbers will be lower than in the original equilibrium ( $\gamma$ and $\bar{z}$ will be lower). Also in this case, the interpretation of the transitional adjustments in the tourism destination is quite intuitive and similar to what presented before: in order to achieve a new equilibrium with slower economic growth and less tourists consumption growth needs to slow down and tourist inflows need to get reduced.

What these very simple examples show is that (environmental-induced) shocks can play a very important role in determining the evolution of the economic and tourism performance of any tourism destination. Thus, policy makers in tourism-based economies where the tourism revenue largely depends upon environmental and natural amenities should be more incline to environmental and climate change problems than others. Indeed, environmental and climatic shocks by affecting not only the long run, but also the short-run dynamics in tourism destinations represent a major threat to their potential development opportunities.

\section{Discussion}

Tourism specialization can represent an important strategy to achieve long-run economic growth and eventually welfare improvements. However, especially when based on environmental assets, it is associated with environmental costs and thus it could even generate the paradoxical result known as "curse of natural resources," suggesting that (natural) resource-rich countries tend to grow more slowly than resource-poor countries (see Sachs and Warner, 2001). Such a result is generally discussed in the context of resource extraction activities, such as oil and mining, but recently some studies analyze this hypothesis also in the context of tourism (Capó et al., 2007; Deng et al., 2014; Holzner, 2011; Sheng and Tsui, 2009). Since many poor and developing countries still have abundant natural resources which provide them with a natural advantage in the production of tourism services, it is important to understand whether and how this outcome can be avoided. Our model suits well to capture and analyze these problems and thus it can help to shed some light on these complex issues. Specifically, it can be used to describe in a stylized fashion the development threats and opportunities of several countries in the Asia-Pacific and the Caribbean region in which tourism is an important source of national income. In fact, the World Travel \& Tourism Council estimates that in 2012 the travel and tourism total contribution in several economies of the region is substantial with peaks even over $90 \%$ of total GDP ${ }^{12}$ (WTTC, 2013).

In particular, the model describes at best the case of small island countries ${ }^{13}$ in which tourism is often seen by local policy makers as the unique way to promote consistent economic growth. However, such a view tends often to forget the problems that tourism specialization may generate in the long run, in order to postpone its regulation in the future, when hopefully economic development is already in a more advanced stage. This is a hazardous choice, especially in small island countries, which are affected by environmental risks (in particular climate change) more strongly than any other country. Indeed, the Intergovernmental Panel on Climate Change (2007) establishes that Tuvalu, Kiribati, and the Marshall Islands in the Pacific, and also the Maldives in the Indian Ocean, are areas particularly vulnerable to the sea-level rise resulting from climate change. Thus, if tourism needs to be the tool to achieve economic development, it is crucial that somehow tourist flows are carefully controlled, balancing economic benefits and environmental costs. Such a situation is critically analyzed in our model, where the tourist number is directly controlled. As the model shows, if the tourist number is kept under control, namely, the number of tourists is optimally determined by some domestic authority (at some level strictly lower that the carrying capacity of the tourism destination), it is possible to reach a sustainable growth path along which increases in income and natural resources go hand in hand, allowing to prevent any conflict 
between short and long term development goals. However, for such an outcome to occur, it is essential that tourist numbers do not grow indefinitely; as shown by equation (3) if $z_{t} \rightarrow \infty$, then both $e_{t} \rightarrow 0$ and $y_{t} \rightarrow 0$ and thus tourism development will end up only in a full exploitation of natural resources without leading to any income gain for the local residents. Therefore, policy makers of tourism-based economies have a very delicate task to accomplish, since, especially in a global framework where international tourism demand keeps increasing over time, without tourism regulation there is very little hope to achieve sustainable development. As we should have learnt from economic history, collapses of societies are not impossible outcomes (Diamond, 2005), thus it is essential to understand how to prevent such an eventual possibility.

\section{Conclusion}

In order to ensure that tourism specialization turns out to be a strategy for long-run sustainable development, it is essential to understand how to trade off the potential associated economic benefits and environmental costs. Indeed, a careful management of tourist numbers in order to achieve a balance between development and the environment is crucial for the tourist region to be economically viable in the long run (Mohan et al., 2007). Several studies point out that identifying the carrying capacity of the tourism destination is critical to ensure that the number of visitors does not exceed a certain threshold beyond which environmental resources would deteriorate excessively.

In order to shed some light on these problems, we develop an endogenous growth model, based on Cerina (2007) and Marsiglio's (2015) works, where the number of tourists is optimally chosen by a social planner who takes into account the implied effects on both the economy and environment. We show that at equilibrium the economy develops along a sustainable BGP, along which the optimal number of tourists and the economic and environmental growth rates are strictly positive. We also show that the optimal number of tourists is strictly smaller than the maximal number of tourists the hosting region can accommodate. This means that focusing on the concept of carrying capacity may be misleading, since this number of tourists may be too large and thus it may be suboptimal. This also suggests that more attention and more resources should be placed on identifying and quantitatively assessing what is the optimal number of tourists who should be allowed in specific tourism destinations. This is even more important than ever in the current framework in which the environment and the planet's climate are under stress and frequently subject to shocks threatening the development potential of tourism-based economies.

\section{Acknowledgements}

I wish to thank the Editor, Stephen Wanhill, and an anonymous referee for their constructive comments on earlier drafts of the article. All remaining errors and omissions are my own sole responsibility.

\section{Declaration of conflicting interests}

The author(s) declared no potential conflicts of interest with respect to the research, authorship, and/or publication of this article.

\section{Funding}

The author(s) received no financial support for the research, authorship, and/or publication of this article.

\section{Supplemental material}

The online appendix is available at http://journals.sagepub.com/doi/suppl/10.5367/te.2015.0535. 


\section{Notes}

1. As Collins (1999) points out, basing carrying capacity on any factors other than ecological considerations is insufficient to ensure the maintenance of minimal natural capital levels over time, which is clearly a basic requirement for achieving sustainability.

2. It is possible that the carrying capacity based on financial and social factors could be at a lower level than that set by the ecosystem. The tourist response toward negative outcomes from tourism, such as congestion, can cause a reduction in the future tourism level, while the attitudes of residents toward negative outcomes, such as congestion and pressure on local infrastructure, can restrict the number of tourists welcomed or allowed to visit the region or feature (Canestrelli and Costa, 1991; Feliziani and Miarelli, 2012). Thus, attitudes of both tourists and residents impact on the sustainability of the tourist industry for any destination. Additionally attitudes of residents can differ depending on whether the residents are involved in, and therefore benefit directly from, the tourism industry or not (Canestrelli and Costa, 1991). The carrying capacity may quickly reach a limit, particularly for small islands, as the ratio of tourists to residents increases causing overcrowding, congestion and increased incidence of crime, drugs, and disease (Commission on Sustainable Development, 1996). See also Marsiglio (2016) for a discussion of the interactions between residents and tourists in a model similar to ours.

3. Note that this situation is consistent with the experience of several localities worldwide, in particular small islands and natural parks where tourists are attracted by the local ecosystem and the natural beauty of the environment. Several tourism sites determine the maximum threshold of visitors to allow on a daily or yearly basis, in order to preserve the environment itself.

4. Similarly, Marsiglio (2015) studies the interaction between tourism, environmental quality, and economic growth, focusing on the optimal amount of resources to devote to environmental protection activities. However, in his model tourist numbers are proportional to the stock of natural resources, thus the determination of the optimal number of tourists is not analyzed. See also Greiner et al. (2001) who analyze the tension between economic development and environmental quality in a framework where a planner tries to maximize the stream of cash flow generated by the tourism industry. Also in their model tourist inflows are not directly controlled but respond to variations in tourism policy.

5. Alternative models often used to investigate the relationship between tourism and growth are based upon dynamic models of trade (Hazari and Sgro, 1995; Schubert et al., 2011) or traditional growth-type models (Hernandez-Leon, 2013; Schubert, 2010).

6. See Marsiglio $(2015,2016)$ for a discussion of the limits of this modeling approach. The same comments apply also in our framework.

7. We assume that natural resources grow without any upper bound, as traditional in the economic growth and environment literature. This implies that we are mainly focusing on renewable resources without taking into account any issue related to the eventual non-renewability of natural capital (Smulders, 1999).

8. The other two scenarios considered by Budowsky (1976), namely, the situation of coexistence and symbiosis, are less interesting from a theoretical point of view since no tradeoffs are involved. Indeed, in such cases tourism, natural resources, tourism capital, and income move in the same direction, and no form of tourism regulation is needed.

9. Indeed, whenever $z_{t} \leq \tilde{z}$ the degradation imposed by tourism is tolerable for the environment since the stock of natural resources does not have to drop; however, if $z_{t}>\tilde{z}$ then the deterioration becomes excessive leading the stock of natural capital to fall. Thus, $\tilde{z}$ represents the threshold value identifying the (ecological) carrying capacity of the tourism destination.

10. Contrarily to Marsiglio (2015), assessing whether also tourism is sustainable is more complex since sustainable tourism is a type of "tourism which meets the needs of present tourists and host regions while 
protecting and enhancing opportunity for the future" (WTO, 1993). Along the BGP, the needs of both present and future tourists are certainly met; however, the number of tourists which can enjoy the tourism services (both in terms of tourism facilities and natural amenities) is constant. This means that even if the international demand for tourism services provided by the tourism destination increases, the number of tourists who can enjoy the services cannot grow to reflect such an increase in demand.

11. In Marsiglio (2015), the number of tourists is predetermined by choices occurred in the past affecting the present stock of environmental assets. Thus, in his model, he cannot conclude anything about the size of tourism activities, and for this reason, we believe our approach is more realistic and useful in terms of policy recommendations.

12. Some specific examples of countries highly dependent upon tourism include Fiji (travel and tourism total contribution to GDP equal to $35.7 \%$ ) and Vanuatu (50.6\%) in the South Pacific Ocean, but also Macau $(92.8 \%)$ in South-East Asia, Maldives (48.7\%) in the Indian Ocean, and Bahamas (47.2\%) and Aruba (82. $8 \%$ ) in the Caribbean region.

13. See Marsiglio (2015) for a discussion of the notion of "luxury of limited choices" (Persaud, 2011), which is often used to describe the development problems experienced by small island countries. "Where countries are physically small and tourism is a large component of the economy, it is critical to invest in preserving and enriching the natural, constructed and social environment. There is no space to waste in a small state. Islands that are dependent on tourism disregard, at their peril, issues such as coastal management, water runoffs, waste management and social issues that keep tourists away-drugs, crime, corruption and general lawlessness." (Persaud, 2011)

\section{References}

Bramwell B (1997) Managing urban tourist numbers. Annals of Tourism Research 24: 248-249.

Briguglio L (2008) Sustainable tourism on small island jurisdictions with special reference to Malta. ARA Journal of Tourism Research 1: 29-39.

Budowsky G (1976) Tourism and environmental conservation: conflict, coexistence or symbiosis? Environmental Conservation 3: 27-31.

Butler RW (1980) The concept of a tourist area cycle of evolution: implications for management of resources. Canadian Geographer 24: 5-12.

Butler RW (1999) Sustainable tourism: a state-of-the-art review. Tourism Geographies 1: 7-25.

Candela G and Cellini R (2006) Investment in tourism market: a dynamic model of differentiated oligopoly. Environmental and Resource Economics 35: 41-58.

Candela G and Figini P (2010) Is there any economics beyond tourism areas? Review of Economic Analysis 2: $256-271$.

Canestrelli E and Costa P (1991) Tourist carrying capacity. A fuzzy approach. Annals of Tourism Research 18: 295-311.

Capó J, Font AR and Nadal JR (2007) Dutch disease in tourism economies: evidence from the Balearics and the Canary Islands. Journal of Sustainable Tourism 15: 615-627.

Cerina F (2007) Tourism specialization and environmental sustainability in a dynamic economy. Tourism Economics 13: 553-582.

Collins A (1999) Tourism development and natural capital. Annals of Tourism Research 26: 98-109.

Commission on Sustainable Development (1996) Sustainable tourism development in small island developing States (United Nations Department of Economic and Social Affairs).

De Albuquerque K and McElroy JL (1992) Caribbean small-island tourism styles and sustainable strategies. Environmental Management 16: 619-632.

Deng T, Ma M and Cao J (2014) Tourism resource development and long-term economic growth - A resource curse hypothesis approach. Tourism Economics 20: 923-938.

Diamond J (2005) Collapse - How Societies Choose to Fail or Survive. London: Penguin Books. 
Feliziani V and Miarelli M (2012) How many visitors should there be in the city? The case of Rome. Review of European Studies 4: 179-187.

Giannoni S and Maupertuis MA (2007) Environmental quality and optimal investment in tourism infrastructures: a small island perspective. Tourism Economics 13: 499-513.

Greiner A, Feichtinger G, Haunschmied JL, et al. (2001) Optimal periodic development of a pollution generating tourism industry. European Journal of Operational Research 134: 582-591.

Hazari BR and Sgro P (1995) Tourism and growth in a dynamic model of trade. Journal of International Trade \& Economic Development 4: 243-252.

Hernandez JM and Leon CJ (2013) Welfare and environmental degradation in a tourism-based economy. Tourism Economics 19: 5-35.

Holzner M (2011) Tourism and economic development: the beach disease? Tourism Management 32: 922-933.

Hovinen GR (2002) Revisiting the destination lifecycle model. Annals of Tourism Research 29: 209-230.

Lozano J, Gómez CM and Rey-Maquieira J (2008) The TALC hypothesis and economic growth theory. Tourism Economics 14: 727-749.

Marsiglio S (2011) On the relationship between population change and sustainable development. Research in Economics 65: 353-364.

Marsiglio S (2015) Economic growth and environment: tourism as a trigger for green growth. Tourism Economics 21: 183-204.

Marsiglio S (2016) Uncertainty, crowding aversion and tourism aversion in tourism destinations. Tourism Economics 22(1): 111-123.

Mohan V, Nabin MH and Sgro PM (2007) Tourism, congestion, taxation, and strategic interaction. International Journal of Tourism Policy 1: 134-152.

Ramsey F (1928) A mathematical theory of saving. Economic Journal 38: 543-559.

Persaud AD (2011) Fostering growth and development in small States through disruptive change: a case study of the Caribbean, CIGI Papers, Caribbean Paper 11.

Rey-Maquieira J, Lozano J and Gómez CM (2004) Land, environmental externalities and tourism development. In: Lanza A, Markandya A and Pigliaru F (eds) The Economics of Tourism and Sustainable Development. Edward Elgar Publishing.

Robertson PE (2002) Demographic shocks and human capital accumulation in the Uzawa-Lucas model. Economics Letter 74: 151-156.

Sachs JD and Warner AM (2001) The curse of natural resources. European Economic Review 45: $827-838$.

Schubert SF (2010) Coping with externalities in tourism: A dynamic optimal taxation approach. Tourism Economics 16: 321-343.

Schubert SF, Brida JG and Risso WA (2011) The impacts of international tourism demand on economic growth of small economies dependent on tourism. Tourism Management 32: 377-385.

Sheng L and Tsui YM (2009) A general equilibrium approach to tourism and welfare: the case of Macao. Habitat International 33: 419-424.

Smulders S (1999) Endogenous growth theory and the environment. In: van den Bergh J (ed) The Handbook of Environmental and Resource Economics. Cheltenham: Edward Elgar, pp. 610-621.

Tisdell CA (1987) Tourism, the environment and profit. Economic Analysis and Policy 17: 13-30.

Wilkinson PF (1989) Strategies for tourism in island microstates. Annals of Tourism Research 16: 153-177.

World Tourism Organization (1993) Sustainable tourism development: guide for local planners. Madrid: WTO.

World Travel \& Tourism Council (2013) Travel \& tourism economic impact 2013 - World. Available at: http://www.wttc.org/site_media/uploads/downloads/world2013_1.pdf 